\title{
SHEAR BOND STRENGTH OF TWO VENEERING COMPOSITE RESINS TO A MODIFIED POLYETHERETHERKETONE (PEEK) MATERIAL: INFLUENCE OF SURFACE PRETREATMENTS AND THERMOCYCLING
}

\author{
Noha A. EL-Wassefy * and Sayed Ghorab**
}

\begin{abstract}
Objective: To research the influence of different surface pretreatment and thermocycling on shear bond strength (SBS) between veneering resins and a modified polyetheretherketone (PEEK) material.

Materials and Methods: (PEEK) specimens were machined and allocated into Four pretreatment groups, Group A; no treatment, Group B; etching with $98 \%$ sulfuric acid for $1 \mathrm{~min}$, Group C; air abrasion with $50 \mu \mathrm{m} \mathrm{Al}_{2} \mathrm{O}_{3}$, and Group D; air abrasion with $110 \mu \mathrm{mAl}_{2} \mathrm{O}_{3}$. Surface roughness (Ra) was determined by a profilometer. Surface morphology of specimens was scanned by a Scanning Electron Microscope. Specimens were treated with Visio.link bond, divided into two subgroups; one veneered with SR Nexco and the other with Crea.lign composites. SBS was tested immediately and after thermocycling. Data were statistically analyzed using ANOVA and Tukey HSD, $\alpha=0.05$.
\end{abstract}

Results: Air abrasion with $110 \mu \mathrm{m}$ alumina significantly increased the surface roughness $(\mathrm{P}<0.001)$. The highest shear bond strength values were observed for sulfuric acid etched group. Specimens veneered with CreaLign showed non-significant higher SBS values than those veneered with SR Nexco ( $P>0.05)$. After thermocycling, all tested groups revealed significant improvement in SBS $(\mathrm{p}<0.001)$.

Conclusions: A modified PEEK material strengthened with $20 \%$ submicron ceramic fillers, could be treated by etching with $98 \%$ sulfuric acid for $1 \mathrm{~min}$, to enhance bond strength to veneering composites and was found to have significant improvement in bond strength after thermocycling.

KEYWORDS: Surface roughness, PEEK, shear bond strength, thermocycling.

*Associate Professor of Dental Materials, Faculty of Dentistry, Mansoura University, Egypt

***ecturer of Dental Materials, Faculty of Dentistry, Mansoura University, Egypt 


\section{INTRODUCTION}

A high performance thermoplastic polymer which is Polyetheretherketone (PEEK), is composed of aromatic backbone molecular chain that is connected interchangeably by ketone or ether functional groups ${ }^{1,2}$ In dentistry, PEEK material can be used as; implants, implant supported bar or clamp and provisional abutment; owing to its outstanding physical and biological characteristics.-6

Unfilled PEEK material has valued mechanical properties; with a flexural strength of nearly $165 \mathrm{MPa}$, and a Young's modulus approximating $3.5 \mathrm{GPa}$, but numerous modification methods as; adding fillers, fiber reinforcement, and blending have been introduced and result in development of novel PEEK-based materials with enhanced characteristics and intended for diverse applications..$^{710}$

A modified PEEK material having 20\% ceramic fillers has been introduced in dentistry (BioHPP; Bredent GmbH, Germany). ${ }^{11-13}$ Due to its strengthening with special ceramic filler, optimized mechanical properties have been created for dental field in the crown and bridge area. This ceramic filler has a small grain size of 0.3 to $0.5 \mu \mathrm{m}$ producing constant homogeneity that is the basis for the extremely good polishing properties resulting in reduced plaque deposition and degree of discoloration.

Prostheses can be easily fabricated from PEEK by either injection molding (thermo-pressing) or CAD/CAM procedures. Furthermore, standard dental burs for polymers can be used for final adjustments. ${ }^{14,15}$

Despite all these positive aspects, the opaque grayish color of PEEK still restricts its application as monolithic restorations. Hence, using additional veneering composite resin to accomplish adequate esthetics is mandatory.

When PEEK is combined with composite resin, the bond strength is low due to its inert hydrophobic performance, surface modification resistance, and low surface energy. ${ }^{16}$ As a result; additional pretreatments of the PEEK surface should be done for enhancement of adhesive properties between PEEK and composite resin materials. ${ }^{17-21}$

Various approaches have been attempted to enhance PEEK surface properties, of these methods air abrasion and sulfuric acid etching do exist. For creating a durable chemical bond between PEEK and veneering resin, the adhesive systems are essential to be used. ${ }^{17,18,22-25}$ Many recent researches proved that a suitable chemical bond to PEEK can be proven with methyl methacrylate (MMA) dental adhesives. ${ }^{22,23}$ Moreover, durable bonding is a prerequisite in order to achieve long-term durability and an acceptable functional outcome. In the oral cavity, daily routine of eating, drinking and breathing can result in temperature changes that produce functional thermal stresses affecting the stability of the bonded interface over time. Thermocycling is a relevant process to replicate in-vitro aging of specimens, because it produces standardized thermal stresses at the interface..$^{26,27}$

Thus, the current study researched the influence of different surface pretreatments and thermocycling on the shear bond-strength (SBS) of two veneering resins to a modified polyetheretherketone material. The null hypothesis was that the bond strength would not be influenced by neither the surface pretreatments nor thermocycling.

\section{MATERIALS AND METHODS}

One type of modified PEEK CAD/CAM materials (breCAM.BioHPP®, Bredent, Senden, Germany) and two types of veneering resins; SR Nexco paste (Ivoclar Vivadent, Schaan, Leichtenstein) and Crea.lign paste (Bredent GmbH \& Co., Senden, Germany) were used in the current study. Table 1 gives the compositions, manufacturers and batch number of the materials that were used in the study. 


\section{Specimen preparation and grouping}

A total of one hundred and twenty diskshaped specimens with dimensions $(10 \mathrm{~mm}$ X 2 $\mathrm{mm}$ ) were cut out of PEEK blanks under profuse water cooling using CAD/CAM technique (Arum x5 400, Doowon Co., Ltd. Daejeon, South Korea). The specimens were polished with 800 grit SiC papers (BuehlerMet II 800, Buehler) to attain a standardized surface. Subsequently, the polished specimens were cleaned using an ultrasonic water bath filled with distilled water for 30 min (Baioden Ultrasonic Cleaner, China) and then air-dried.

The specimens were fixed in blocks made of auto-polymerizing acrylic resin, exposing only top surface for treatment application and bonding. The specimens were categorized into four groups ( $\mathrm{n}=32$ per group; 12 specimens for studying the surface morphology and surface roughness, and 20 specimens for shear bond strength measurement) according to surface treatment methods as follow; Group A (control): no treatment, Group B (sulfuric acid etching): surfaces were etched for 1 min with 98\% sulfuric acid (Sigma-Aldrich; St. Louis, MO, USA) then carefully rinsed with distilled water for $1 \mathrm{~min}$, Group C (50 $\mu \mathrm{m}$ airborne particle abrasion): surfaces were air abraded with $50 \mu \mathrm{m}$ aluminum oxide (JNBP-2, Jianian Futong Medical Equipment Co. Ltd., Tianjin, China) at 2 bar pressure for $10 \mathrm{sec}$ at a $10 \mathrm{~mm}$ distance, then rinsed, and air-dried for $20 \mathrm{sec}$, and Group D (110 $\mu \mathrm{m}$ airborne particle abrasion): air-abrasion with $110 \mu \mathrm{m}$ aluminum oxide as described with Group C.

\section{Measurement of surface roughness}

Surface roughness values were measured by a profilometer (SURFTEST SJ-201, Mitutoyo Corp., Kawasaki, Japan). The stylus moved back and forth across each specimen, five readings were recorded, and the mean roughness value $(\mathrm{Ra})$ of the specimen was calculated. The cut-off length was $0.8 \mathrm{~mm}$, at $0.5 \mathrm{~mm} / \mathrm{s}$ scanning speed. The resolution of the recorded data was $0.01 \mu \mathrm{m}$.

TABLE (1) Materials used in the study

\begin{tabular}{|c|c|c|}
\hline Materials & Composition & Manufacturer/Batch No. \\
\hline $\begin{array}{l}\text { PEEK material } \\
\text { breCAM.BioHPP }\end{array}$ & $\begin{array}{l}\text { Polyetherether ketone, } 20 \mathrm{wt} \% \text { Titaniun dioxide ceramic- } \\
\text { filled }\end{array}$ & $\begin{array}{l}\text { Bredent GmbH \& Co., Senden, } \\
\text { Germany/462597 }\end{array}$ \\
\hline $\begin{array}{l}\text { Veneering composites } \\
\qquad \begin{array}{c}\text { SR Nexco paste } \\
\text { dentine }\end{array}\end{array}$ & $\begin{array}{l}\text { Polymer matrix: UDMA,AliphaticDimethacrylate } \\
\text { (Decandioldimethacrylate)(16.9 wt } \%) \\
\text { - Filler: silicon dioxide }(19.8 \mathrm{wt} \%) \text { prepolymer and co- } \\
\text { polymer which consists of pre-polymerized ground } \\
\text { up UDMA matrix and inorganic microfiller particles } \\
(62.9 \% \mathrm{wt} .) \\
\text { - } \\
\text { Additional contents are stabilizers, catalysts }(0.4 \mathrm{wt} \%) \\
\text { and pigments }(0.1-0.3 \mathrm{wt} \%) \text {. }\end{array}$ & $\begin{array}{l}\text { IvoclarVivadent, } \\
\text { Schaan, Leichtenstein/S38493 }\end{array}$ \\
\hline $\begin{array}{l}\text { Crea.lign paste } \\
\text { dentine }\end{array}$ & $\begin{array}{l}\text { Various acrylate oligomers, silanized inorganic fillers } \\
\text { ( } 50 \mathrm{wt} \% \text { opalescent ceramic fillers), catalysts and color } \\
\text { pigments. }\end{array}$ & $\begin{array}{l}\text { Bredent GmbH \& Co., Senden, } \\
\text { Germany/ N160407 }\end{array}$ \\
\hline $\begin{array}{l}\text { Primer } \\
\text { Visio.link }\end{array}$ & MMA, PETIA, photoinitiators & $\begin{array}{l}\text { Bredent GmbH \& Co., Senden, } \\
\text { Germany/153141 }\end{array}$ \\
\hline
\end{tabular}




\section{Surface Morphology analysis}

The surface morphology of each treated group was studied using a scanning electron microscope (SEM, JSM-6510LV, JEOL, Tokyo, Japan). For this purpose, two specimens from each surface treatment group were produced as previously mentioned, cleaned in an ultrasonic bath with $96 \%$ ethanol for 2 min and then air dried. Afterward, specimens were affixed on metallic stubs, gold sputter-coated (SPIMODULE $^{\mathrm{TM}}$, SPI Supplies, USA), and examined under a SEM to detect topography of the treated surfaces (X 10,000).

\section{Shear bond strength testing}

A $10 \mathrm{~mm}$ cut of a double sided tape with punched hole diameter of $5 \mathrm{~mm}$ was positioned on the PEEK surface to outline the bonding area. Subsequently, visio.link primer (Bredent $\mathrm{GmbH} \& \mathrm{Co}$., Senden, Germany) was applied to the surface using a microbrush and then immediately polymerized for 90 sec (Bre.lux Power Unit; bredent GmbH \& Co., Senden, Germany) according to the manufacturer recommendation. Each pretreatment group was randomly divided into two subgroups $(n=10)$ to be used with two veneering resins i) SR Nexco paste (Ivoclar Vivadent,Schaan, Leichtenstein) and ii) Crea.lign paste (Bredent GmbH \& Co., Senden, Germany). For this purpose, a split Teflon mold (6 $\mathrm{mm}$ diameter, $2 \mathrm{~mm}$ thickness) was placed surrounding the visio.link, filled with veneering resin and then polymerized with Bre.lux power unit $\left(190-220 \mathrm{~mW} / \mathrm{cm}^{2}\right)$ for $6 \mathrm{~min}$, according to manufacturer's recommendation.

Both bonding sub-groups were divided into two groups of 5 specimens each, and either being stored in $37^{\circ} \mathrm{C}$ distilled water for $24 \mathrm{~h}$ or subjected to 10,000 thermal-cycles from $5^{\circ} \mathrm{C}$ to $55^{\circ} \mathrm{C}$, at $20 \mathrm{sec}$ dwell time between baths in a thermocycler machine (Theromocycler, Robota, Alexandria, Egypt).

Shear bond strength (SBS) testing was conducted on a Universal Testing Machine (Instron 3345, England). The applied crosshead speed was $0.5 \mathrm{~mm} / \mathrm{min}$ until debonding occurred. SBS values were recorded in mega-Pascal (MPa). After debonding, the specimens were inspected under an optical stereomicroscope (Olympus model SZ-PT, Tokyo, Japan) at X 40 magnification to determine the failure mode, either adhesive failure; if no composite remnant was left on PEEK surface, or mixed failure; if composite remnants were partly left on PEEK surface, or cohesive failure in which fracture occurs in either composite resin or PEEK.

\section{Statistical analysis}

Data distribution was tested for normality using Kolmogorov-Smirnov and Shapiro-Wilk tests. Data were normally distributed. Surface roughness $(\mu \mathrm{m})$ data were analyzed by one-way analysis of variance (ANOVA). SBS (MPa) data were statistically analyzed by three-way ANOVA considering three factors which are type of surface treatment, type of veneering resin and thermal treatment, to detect the interaction between the independent variables. Tukey HSD test was applied to define any significant differences among the groups. Relative frequencies (\%) of failure types of each group were computed. The Statistical Package of Social Sciences (SPSS) version 21 was used at a significance level of $\alpha=0.05$.

\section{RESULTS}

Surface roughness $(\mu \mathrm{m})$ value analysis with one way ANOVA revealed that surface roughness was significantly affected by the surface treatment method ( $p<0.001)$ as shown in Table 2. The means and standard deviations of average surface roughness values $(\mu \mathrm{m})$ with their significant differences are shown in Table 3. Comparing the mean surface roughness of the tested groups showed that $110 \mu \mathrm{m}$ $\mathrm{Al}_{2} \mathrm{O}_{3}$ sandblasting group exhibited the highest value $(4.19 \pm 0.56)$ compared with other surface treatment approaches, while control group showed the lowest value $(0.33 \pm 0.18)$. In addition, no statistically significant difference was found between $50 \mu \mathrm{m}$ $\mathrm{Al}_{2} \mathrm{O}_{3}$ sandblasting and sulfuric acid treated groups. 
TABLE (2) One-way ANOVA results for surface roughness $(\mathrm{Ra})$ of different groups

\begin{tabular}{|c|c|c|c|c|c|}
\hline Source & df & $\begin{array}{c}\text { Sum of } \\
\text { Squares }\end{array}$ & $\begin{array}{c}\text { Mean } \\
\text { Square }\end{array}$ & F & P \\
\hline $\begin{array}{c}\text { Between } \\
\text { Groups }\end{array}$ & 3 & 41.500 & 13.833 & 25.796 & 0.000 \\
\hline $\begin{array}{c}\text { Within } \\
\text { Groups }\end{array}$ & 16 & 8.580 & 0.536 & & \\
\hline Total & 19 & 50.080 & & & \\
\hline
\end{tabular}

Statistically significant difference at $P<0.05$

Figure 1 shows scanning electron photomicrographs of control and treated PEEK specimens at magnification of X5000. Figure 1 (A) shows SE photomicrograph of a representative control specimen; they have a relatively smooth surface devoid of surface texture. Figure 1(B) shows SE photomicrograph of a representative sulfuric acid etched specimen; the surface topography is extensively different than the control with numerous levels and summits, porosities and intervening grooves do exist in-between, scattered globular structures appear to be sculptured and firmly attached to the matrix. Figure $1(\mathrm{C})$ shows SE photomicrograph of a representative specimen treated with airborne particles abrasion $(50 \mu \mathrm{m}$ $\mathrm{Al}_{2} \mathrm{O}_{3}$ ); the surface topography has abraded textures with some porosity, grooves and some superficial particles. The overall architecture looks shallower than the acid etched group. Figure 1(D) shows SE photomicrograph of a representative specimen treated with airborne particles abrasion $(110 \mu \mathrm{m}$ $\mathrm{Al}_{2} \mathrm{O}_{3}$ ); the surface topography looks more or less close to group $\mathrm{C}$, but more prominent architecture with obvious porosity and far deepened grooves.
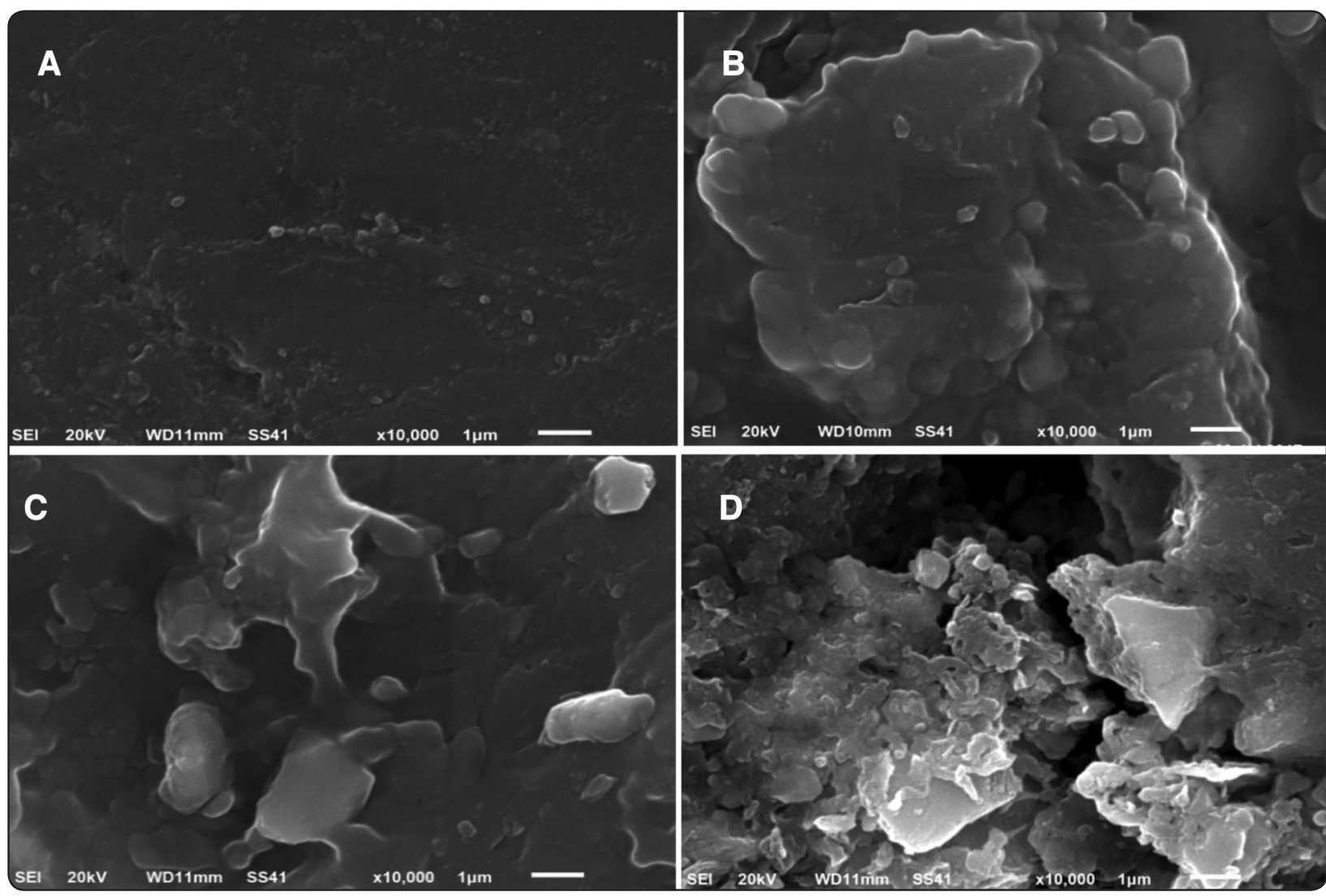

Fig. (1) SE micrographs of pretreated PEEK surface at magnification 10000x. A: Non-treated, B: sulfuric acid etching, C: $50 \mu \mathrm{m}$ sandblasting, and D: $110 \mu \mathrm{m}$ sandblasting 
TABLE (3) Means (Standard Deviation) of surface roughness (Ra) in $\mu \mathrm{m}$ for each group and Tukey analysis

\begin{tabular}{|l|c|}
\hline Groups & Mean (SD) \\
\hline No treatment & $0.33(0.18)^{\mathrm{a}}$ \\
\hline Sulfuric acid etched & $2.56(1.27)^{\mathrm{bc}}$ \\
\hline $\mathbf{5 0} \boldsymbol{\mu m}$ sandblasting & $3.21(0.64)^{\mathrm{bc}}$ \\
\hline $\mathbf{1 1 0} \boldsymbol{\mu m}$ sandblasting & $4.19(0.56)^{\mathrm{d}}$ \\
\hline
\end{tabular}

Mean with the same superscript letter are not significantly different

Three-way ANOVA of the bond strength data in MPa disclosed that the SBS was not significantly affected by neither the type of treatment nor by the type of veneering $(\mathrm{P}>0.05)$. On the other hand, it was significantly affected by thermocycling $(\mathrm{P}<0.001)$. There was no significant interaction between type of treatment, type of veneering and thermocycling $(\mathrm{P}=$ 0.0966) as shown in Table 4. The mean of the SBS values (MPa) and standard deviations are presented in Table 5. Comparing the means of immediate SBS, it could be seen that group B (sulfuric acid etched group) exhibited the highest value for both types of veneering resins (SR Nexco: $6.51 \pm 1.54$ and CreaLign: $6.56 \pm 0.40$ ) as compared to other surface treatments groups, while group A (control group) showed the lowest SBS value (SR Nexco: $2.17 \pm 0.89$ and CreaLign: $4.80 \pm 2.68)$. Generally, enhancements in SBS values (MPa) were found in the following groups respectively: sulfuric acid etching group, then $50 \mu \mathrm{m}$ sandblasting group, then $110 \mu \mathrm{m}$ sandblasting, and lastly control group as presented in Table 5. According to the type of veneering resin, CreaLign composite resin showed non-significant increased SBS compared to SR Nexco composite resin in all groups $(\mathrm{P}>0.05)$ (Table 5). For the level of thermocycling, significant improvement in SBS was observed for all studied groups after thermocycling $(\mathrm{P}<0.001)$.

Stereomicroscopic examination at the debonding sites showed three modes of failure; adhesive failure when no composite remnant was left on the PEEK surface, mixed failure when composite remnants were partially left on PEEK surface and cohesive failure within composite resin. These modes of failure were varied between the tested groups as shown in Figure 2, where control and $110 \mu \mathrm{m}$ sandblasting groups showed more adhesive failure, while sulfuric acid etching and $50 \mu \mathrm{m}$ sandblasting groups showed more cohesive and mixed ones. Moreover, all studied groups showed less adhesive failure after thermocyling.

TABLE (4) Three-way ANOVA results for SBS (MPa) of all tested groups

\begin{tabular}{|c|c|c|c|c|c|}
\hline $\begin{array}{c}\text { Source of } \\
\text { variation }\end{array}$ & $\begin{array}{c}\text { Sum of } \\
\text { Squares }\end{array}$ & Df & $\begin{array}{c}\text { Mean } \\
\text { Square }\end{array}$ & F & P \\
\hline Surface treatment & 98.127 & 3 & 32.709 & 2.75 & 0.0558 \\
\hline Veneering & 36.557 & 1 & 36.557 & 3.07 & 0.0876 \\
\hline $\begin{array}{c}\text { Thermocycling } \\
* \text { veneering }\end{array}$ & 261.136 & 1 & 261.136 & 21.93 & $<.0001$ \\
\hline $\begin{array}{c}\text { Surface treatment } \\
* \text { thermocycling }\end{array}$ & 39.427 & 3 & 13.142 & 1.10 & 0.3592 \\
\hline $\begin{array}{c}\text { Veneering * } \\
\text { thermocycling }\end{array}$ & 0.000 & 1 & 0.000 & 0.00 & 1.0000 \\
\hline $\begin{array}{c}\text { Surface treatment } \\
* \text { veneering * } \\
\text { thermocycling }\end{array}$ & 80.734 & 3 & 26.911 & 2.26 & 0.0966 \\
\hline $\begin{array}{c}\text { Total } \\
\text { Errors }\end{array}$ & 464.356 & 39 & 11.906 & & 0.7104 \\
\hline $\begin{array}{c}\text { treatment } \\
\text { theng }\end{array}$ & 996.839 & 54 & & & \\
\hline
\end{tabular}

Statistically significant difference at $P<0.05$ 
TABLE (5) Means (Standard Deviations) of shear bond strength (SBS) in MPa for each group and Tukey analysis.

\begin{tabular}{|c|c|c|c|c|}
\hline \multirow{2}{*}{ Surface Treatment } & \multicolumn{2}{|c|}{ Immediate (0 TC) } & \multicolumn{2}{|c|}{ Thermocycling (10000 TC) } \\
\hline & SR Nexco & CreaLign & SR Nexco & CreaLign \\
\hline Control (No treatment) & $2.17(0.89)^{\mathrm{d}}$ & $4.80(2.68)^{\mathbf{c d}}$ & $5.37(0.99)^{\mathbf{c d}}$ & $7.76(8.18)^{\mathbf{a} b \mathbf{c d}}$ \\
\hline Sulfuric acid etched & $6.51(1.54)^{\mathrm{cd}}$ & $6.56(0.40)^{\mathbf{c d}}$ & $7.25(6.54)^{\mathbf{b c d}}$ & $13.80(5.82)^{\mathrm{a}}$ \\
\hline $50 \mu \mathrm{m}$ sandblasting & $4.44(1.27)^{\mathbf{c d}}$ & $6.49(1.14)^{\mathbf{c d}}$ & $8.29(5.11)^{\mathbf{a b c ~ d}}$ & $7.29(5.14)^{\mathbf{b c d}}$ \\
\hline $110 \mu \mathrm{m}$ sandblasting & $2.97(0.62)^{d}$ & $6.14(0.46)^{\mathbf{c d}}$ & $13.60(3.20)^{\mathbf{a} b}$ & $10.71(2.06)^{\mathbf{a} b \mathbf{c}}$ \\
\hline
\end{tabular}

Mean with the same superscript letter are not significantly different.

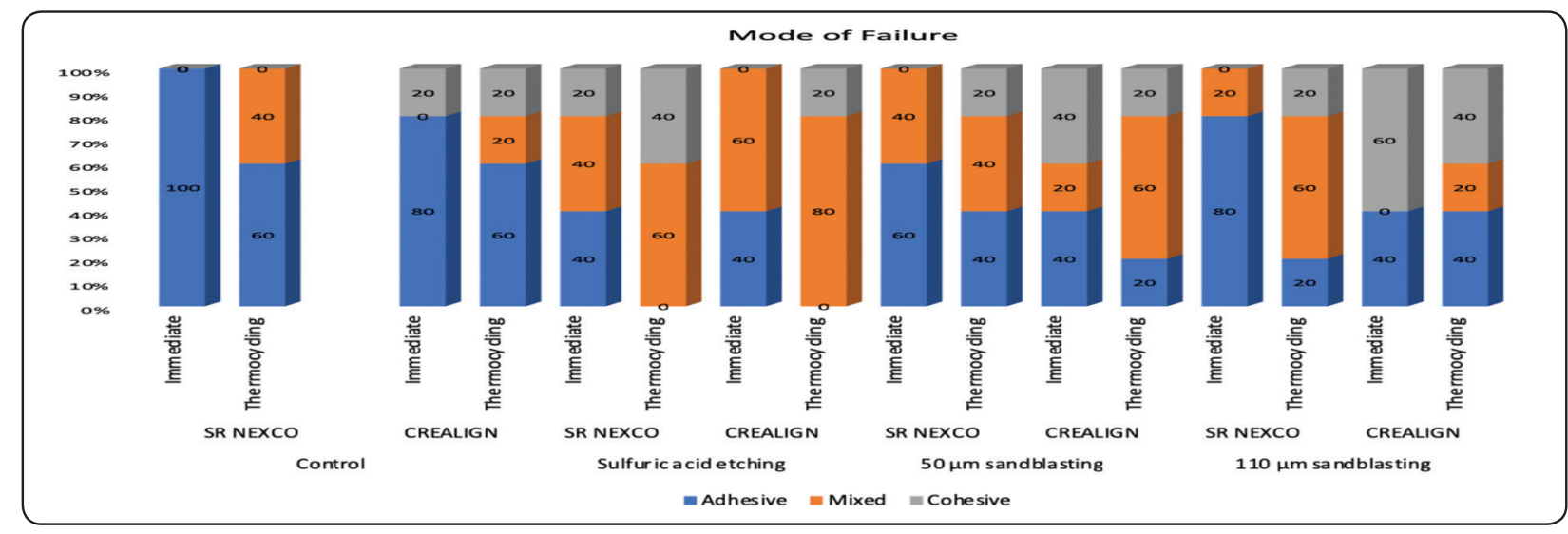

Fig. (2) Relative frequencies (\%) of failure patterns of different groups tested (adhesive failure between PEEK and veneering resin, mixed adhesive and cohesive within composite resin).

\section{DISCUSSION}

In this study, modified PEEK material reinforced with ceramic fillers was used that prominently increases the biomechanical properties of PEEK, making it more proper to be used as fixed dental prostheses, mainly in areas subjected to high stresses. The successful and robust bonding to PEEK is a necessity for its application as a dental prosthetic material. This study investigated the effect of surface pretreatment methods and thermocycling on SBS of modified PEEK material to two different veneering resins.

The null hypothesis was partially rejected, as it was shown that the bond strength was not significantly affected by the type of treatment and significantly affected by thermocycling.

During the adhesion procedure, the surface of the PEEK material should be sufficiently rough in order to obtain appropriate mechanical retention. However, the high strength and hardness of PEEK material impede the surface roughening process. In this study, different pretreatment procedures were used for enhancing the bond strength of the modified PEEK material. Furthermore, shear bond strength test was used since it could simply reproduce the clinical situation and it is more appropriate for evaluating bonding abilities of veneering resins to PEEK. This study showed that etching of PEEK with $98 \%$ concentrated sulfuric acid revealed 
the highest shear bond strength for both types of veneering resins. This can be explained by the fact that sulfuric-acid generated sulfonate groups ($\mathrm{SO}_{3}$ ) in the PEEK polymer chains which became chemically cross-linked to methylmethacrylate based adhesives..$^{22,23,28}$ Additionally, diffusion of resin tags into PEEK surface pores and pits resulted in micromechanical bonding. ${ }^{25}$ This result is correlated with the topography of the treated surface which revealed that the modified PEEK surface became porous and permeable to adhesives after 98\% sulfuric acid treatment for $1 \mathrm{~min}$, as shown in Figure (1b).

The results also showed that air abrasion with $110 \mu \mathrm{m}$ alumina did not distinctly improve the bond strength to veneering resins; however, it increased the ( $\mathrm{Ra}$ ) values in comparison to other tested groups. A possible explanation is that the rough surfaces and high porosities created on PEEK surface with coarse alumina particles may have adversely affected the adhesives infiltration and caused some weak points of bond interfaces. ${ }^{24}$ This result is correlated with topography of the treated surface, as Figure (1d) showed more prominent architecture with obvious porosity and far deepened grooves. This result goes with the finding obtained by Stawarczk B et al. ${ }^{29}$, who perceived observed that; however the highest surface roughness values were achieved in $110 \mu \mathrm{m}$ air abraded group, the maximum SBS were observed for the acid etched group.

Stability of bonded interface over time should be attained in order to achieve an adequate functional outcome and long-term durability. Temperature fluctuations that happen in the oral cavity because of eating, drinking and breathing that happen daily can produce functional thermal stress affecting the bonding durability. Under in-vitro conditions, the thermocycling test could replicate oral temperature fluctuations to assess the restorations durability. In this study, a thermocycling test machine with 10,000 in-vitro thermal cycles, representing 1 year of in-vivo usage, was used to assess the restorations durability. It is an applicable method that simulates in-vitro aging of specimens because it produces standardized thermal stresses at the interface. ${ }^{26,30}$ In this study, a significant improve in shear bond strength values was detected after thermocycling. Previous researches ${ }^{19,31}$ have stated that higher bond strength values could be observed after thermocycling due to post-polymerization in the interface area of the PEEK surface, the adhesive system and the veneering resin.

The fracture analysis for all adhesive tested groups disclosed that modes of failures were adhesive, mixed and cohesive. It was found that the amount of the substrate fracture is often indicative to the retentive adhesive strength. Thus, the mode of failure detected support the result of the bond strength values achieved in this study. Moreover, the occurrence of mixed and cohesive failures might be attributed to the unequal stress distribution at the bonding interface at the time of the loading procedure. ${ }^{17}$

A general limitation of the present study is that invitro experimentations cannot totally symbolize the mouth's actual environment. Hence, supplementary in-vivo studies are needed to report the long-term bonding robustness.

\section{CONCLUSIONS}

Based on the results and within the limitation of this study, the following conclusions can be made.

1. The highest shear bond strength values can be attained when etching with $98 \%$ sulfuric acid for $1 \mathrm{~min}$.

2. Despite the fact that $110 \mu \mathrm{m}$ air abrasion showed the highest roughness, it did not clearly increase the bond strength to veneering resins.

3. Significant improvement in shear bond strength was observed for all studied groups after thermocycling. 


\section{CONFLICT OF INTEREST}

The authors declare no potential conflicts of interest.

\section{ACKNOWLEDGMENTS}

The authors would like to thank Professor Dr. Nazem Shalaby, Professor of Statistics and Dean of the Faculty of Agriculture, Mansoura University, Egypt, for his contribution in analyzing and revising the statistical results of this work.

\section{REFERENCES}

1. Kurtz SM, Devine JN. PEEK biomaterials in trauma, orthopedic, and spinal implants. Biomaterials 2007; 28:4845-69.

2. Toth JM, Wang M, Estes BT, Scifert JL, Seim HB, Turner AS. Polyetheretherketone as a biomaterial for spinal applications. Biomaterials 2006;27:324-4.

3. Tetelman ED, Babbush CA. A new transitional abutment for immediate aesthetics and function. Implant Dent 2008; 17:51-8.

4. Santing HJ, Meijer HJ, Raghoebar GM, Ozcan M. Fracture strength and failure mode of maxillary implant-supported provisional single crowns: A comparison of composite resin crowns fabricated directly over PEEK abutments and solid titanium abutments. Clin Implant Dent Relat Res 2012;14:882-89.

5. Bayer S, Komor N, Kramer A, Albrecht D, Mericske-Stern R, Enkling N. Retention force of plastic clips on implant bars: A randomized controlled trial. Clin Oral Implants Res 2012;23:1377-74.

6. Tannous F, Steiner M, Shahin R, Kern M. Retentive forces and fatigue resistance of thermoplastic resin clasps. Dent Mater 2012;28:273-8.

7. Chu XX, Wu ZX, Huang RJ, Zhou Y, Li YF. Mechanical and thermal expansion properties of glass fibers reinforced PEEK composites at cryogenic temperatures. Cryogenic 2010;50:84-8.

8. Abu Bakar MS, Cheng MHW, Tang SM, Yu SC, Liao K, Tan CT, Khor KA, Cheang P. Tensile properties, tension-tension fatigue and biological response of polyetheretherketone-hydroxyapatite composites for load- bearing orthopedic implants. Biomaterials 2003;24:224550 .

9. Vail JR, Krick BA, Marchman KR, Sawyer WG. Polytetrafluoroethylene (PTFE) fiber reinforced polyetheretherketone (PEEK) composites. Wear 2011; 270:737-41.

10. Wang Q, Xue Q, Sheng W, Zhang J. The friction and wear properties of nanometer $\mathrm{ZrO} 2$-filled PEEK. J Appl Sci1998;69:135-41.

11. Seferis JC. Polyetheretherketone (PEEK): processingstructure and properties studies for a matrix in high performance composites. Polymer Composites 1986; 7:158-69.

12. Katzer A, Marquardt H, Westendorf J, Wening JV, Von Foerster G. Polyetheretherketone cytotoxicity and mutagenicity in vitro. Biomaterials 2002;23:1749-59.

13. Rivard $\mathrm{CH}$, Rhalmi S, Coillard C. In vivo biocompatibility testing of peek polymer for a spinal implant system: a study in rabbits. J Biomed Mater Res B Appl Biomater 2002;62:488-98.

14. Rzanny A, Gobel F, Fachet M. BioHPP summary of results for material tests. Research Report., Department of Materials and Technology, University of Jena, Jena, Germany, 2013.

15. Adler S, Kistler S, Kistler F, Lermer J, Neugerbauer J. Compression-moulding rather than milling: a wealth of possible applications for high performance polymers. Quintessence Zahntech 2013;39:376-84.

16. Noiset O, Schneider YJ, Marchand-Brynaert J. Adhesion and growth of $\mathrm{CaCO}_{2}$ cells on surface-modified PEEK substrata. J Biomater Sci Polym Ed 2000;11:767-86.

17. Zhou L, Qian Y, Zhu Y, Liu H, Gan K, Guo J. The effect of different surface treatments on the bond strength of PEEK composite materials. Dent Mater 2014;30:e209-e215.

18. Schmidlin PR, Stawarczyk B, Wieland M,Attin T, Hämmerle CH, Fischer J. Effect of different surface pretreatments and luting materials on shear bond strength to PEEK. Dent Mater 2010; 26:553-9.

19. Stawarczyk B, Keul C, Beuer F, Roos M, Schmidlin PR. Tensile bond strength of veneering resins to PEEK: impact of different adhesives. Dent Mater J 2013; 32: 441-8.

20. Keul C, Liebermann A, Schmidlin PR, Roos M, Sener B, Stawarczyk B. Influence of PEEK surface modification on their properties and bond strength to veneering resin composites. J Adhes Dent 2014; 16: 383-92. 
21. Rosentritt M, Preis V, Behr M, Sereno N, Kolbeck C. Shear bond strength between veneering composite and PEEK after different surface modifications. Clin Oral Investig 2015;19:739-44.

22. Kern M and Lehmann F. Influence of surface conditioning on bonding to polyetheretherketone (PEEK). Dent Mater 2012;28:1280-83.

23. Hallmann L, Mehl A, Sereno N, Hämmerle CHF. The improvement of adhesive properties of PEEK through different pre-treatments. Appl Surf Sci 2012; 258:7213-18.

24. Sproesser O, Schmidlin PR, Uhrenbacher J, Roos M, Gernet W, Stawarczyk B. Effect of sulfuric acid etching of polyetheretherketone on the shear bond strength to resin cements. J Adhes Dent 2014; 16: 465-72.

25. Silthampitag $\mathrm{P}$, Chaijareenont $\mathrm{P}$, Tattakorn $\mathrm{K}$, Banjongprasert C, Takahashi H, Arksornnukit M. Effect of surface pretreatments on resin composite bonding to PEEK. Dent Mater J 2016; 35: 668-74.

26. Gale MS and Dervell BW. Thermal cycling process for laboratory testing of dental restorations. J Dent 1999; 27:89-99.
27. Nakamura T, Wakabayashi $K$, Kinuta S, Nishida $H$, Miyamae M, Yatani H. Mechanical properties of new selfadhesive resin-based cement. J Prosthodont Res 2010; 54: $59-64$.

28. Chaijareenont P, Prakhamsai S, Silthampitag P, Takahashi H, Arksornnukit M. Effects of different sulfuric acid etching concentrations on peek surface bonding to resin composite. Dent Mater J 2018;37:385-92.

29. Stawarczyk B, Beuer F, Wimmer T, Jahn D, Sener B, Roos M, Schmidlin PR. Polyetheretherketone-A suitable material for fixed dental prostheses? J Biomed Mater Res Part B 2013:101B:1209-16.

30. Zhou L, Qian Y, Gan K, Liu H, Liu X, Niu D. Effect of different surface treatments and thermocycling on shear bond strength to polyetheretherketone. High Performance Polymers 2017;29:87-93

31. Piwowarczyk A, Lauer HC, Sorensen JA. In vitro shear bond strength of cementing agents to fixed prosthodontic restorative materials. J Prosthet Dent 2004;92:265-73. 